\title{
Age-related changes in quality and fertility of porcine semen
}

\author{
Ioannis A Tsakmakidis ${ }^{1 *}$, Tarek AA Khalifa ${ }^{2}$, Costas M Boscos ${ }^{1}$ \\ ${ }^{1}$ Clinic of Farm Animals, Faculty of Veterinary Medicine, Aristotle University of Thessaloniki, St. Voutyra 11, 54 627, Thessaloniki, Greece, \\ 2 EquiBiotech - Research Services in Animal Breeding, Thessaloniki, Greece
}

\begin{abstract}
The aim of this study was to investigate the effect of boar age on quality traits and fertility of liquid-stored semen. Boars were allocated into 3 age groups: 7-10 months (young), 18-33 months (mature), 51-61 months (old). Ejaculates of $\geq 200 \times 10^{6} \mathrm{sperm} / \mathrm{ml}$ and $85 \%$ total motile sperm were extended to $30 \times 10^{6} \mathrm{sperm} / \mathrm{ml}$, stored at $17-18^{\circ} \mathrm{C}$ and used within $12-24 \mathrm{~h}$ for artificial insemination (AI) of $2062 \mathrm{multiparous}$ sows. After $24 \mathrm{~h}$ of storage, aliquots of diluted semen were assessed for sperm progressive motility (SPM), incidence of sperm chromatin instability (SCI), proportion of live morphologically normal sperm (LMNS) and head morphometry of LMNS. The results showed that young boars had higher percentages of SCI and lower proportions of LMNS than those of the mature $(\mathrm{p}<0.05)$ and old $(\mathrm{p}<0.001)$ boars, respectively. Sperm head dimensions of young and old boars were greater $(\mathrm{p}<0.03-0.001)$ than those of mature boars. The farrowing rate of young boars $(65 \%)$ was significantly lower $\left(p<0.001 ; \chi^{2}=30-61\right)$ than those of the mature $(87.2 \%)$ and old $(84.7 \%)$ boars. The relationship between sperm head dimensions and boar fertility was non-significant. In conclusion, boar age is an important physiological factor contributing to the success of swine AI.
\end{abstract}

Key terms: boar age; boar semen; morphology; morphometry; sperm chromatin.

\section{INTRODUCTION}

Artificial insemination (AI) performance in pig farms requires evaluation of semen characteristics, aiming to ensure its quality before service. Male aging is accompanied with hormonal and cellular changes affecting sperm quality as well as its fertilizing capacity. Kennedy and Wilkins (1984) found that maximum semen volume and sperm concentration could be obtained from boars of 24-29 months old, while according to Smital (2009) sperm output tended to increase up to boar age of 3.5 years. For basic semen characteristics, an age-related decrease in testosterone has been reported (Araujo and Wittert, 2011). The age-related reduction of testosterone is complex, involving intrinsic and extrinsic factors to the Leydig cells (Midzak et al., 2009). It is known that boar age and semen quality are taken into account as factors for boar culling. Replacement rates are variable, but generally boars are replaced about their third birthday unless they are truly exceptional, in which case they are kept up to 5 years of age. Huang et al. (2010) demonstrated that Duroc breed boars could be used as semen donors at least until the age of 4 years, but their reproductive longevity could be extended up to 6 years old if they were kept strictly in a temperature lower than $22{ }^{\circ} \mathrm{C}$.

The boar age factor has been investigated concerning its effect on ejaculate volume, sperm concentration, motility and abnormalities (Wolf and Smital, 2009). Moreover, morphology of spermatozoa has been used in fertility evaluation of the male (Waberski et al., 1990; Abu Hasan Abu et al., 2011) and it is recommended as part of the spermiogram for domestic animals (Rodriguez-Martinez, 2003). In addition, sperm head morphometry has been shown to correlate with fertility in various species including pigs (Pena et al., 2005). Gil et al. (2009) showed that sperm motion characteristics of porcine spermatozoa are affected by head morphometry. However, to our knowledge, there is no report of a study on the influence of boar age on sperm head dimensions.
Sperm chromatin integrity is an independent quality parameter that may have a better diagnostic value than the standard semen analysis (Sun et al., 1997). Previous studies demonstrated that chromatin integrity reflected the possible disorders in spermatogenesis and epididymal sperm maturation (Hingst et al., 1995). It is directly related to boar fertility (Evenson et al., 1994) and has a very important contribution to the normal development of the early embryo (Ahmadi and $\mathrm{Ng}$, 1999). In humans, paternal age is positively correlated with increased DNA damage in men of infertile couples (Singh et al., 2003). On the other hand, boar spermatozoa have a highly condensed chromatin where protamines pack tightly and protect the haploid DNA (Rodriguez-Martınez et al., 1990). However, in vitro handling of spermatozoa including semen storage has been discussed as a factor that may compromise chromatin-DNA integrity (BoeHansen et al., 2005). Other studies analyzed the relationship between chromatin integrity and sperm morphology. Although the relationship between sperm head dimensions and chromatin status remains controversial, many of the studies reported no relationship between them (Saravia et al., 2007; Gassuto et al., 2011). Aiming at improving the predictive value of semen analysis, earlier investigations supported a relation between field fertility and chromatin integrity after the combination of sperm traits such as live normal spermatozoa and stability of the deoxyribonucleic acid complex (BoeHansen et al., 2008; Tsakmakidis et al., 2010).

The objective of this study was to investigate the influence of boar age on some sperm quality traits (motility, viability, normal morphology, morphometry and chromatin integrity) and the fertility of liquid-stored semen. An additional objective of this study was to determine the possible differences in sperm head dimensions according to boar age (young, mature and old) and to relate them to field fertility. 


\section{MATERIALS AND METHODS}

\subsection{Chemical reagents}

Unless otherwise noted, chemicals were purchased from Sigma-Aldrich Co., Greece. Buffers and staining solutions were sterilized by filtration through $0.22-\mu \mathrm{m}$ filters.

\subsection{Animals}

The study was conducted over a 5-month period (November, 2009 to March, 2010) in a private enterprise (Thessaloniki, Greece) and involved seventeen crossbred boars and 2062 sows. Boars of similar sire were imported from a European breeding company. Boars were selected according to the normal semen quality in routine tests (sperm concentration, morphology and motility). They were individually penned and fed on a ration formulated according to NRC standards. All boars were sexually active and under a weekly semen collection regimen throughout the study period.

\subsection{Experimental design}

Boars were allocated into three groups. Each group consisted of 5-7 boars aged 7-10 months (young, $n=5$ ), 18-33 months (mature, $\mathrm{n}=7$ ) or 51-61 months (old, $\mathrm{n}=5$ ). Semen samples were collected (1-2 ejaculates/boar/week) by the 'gloved hand' technique. Gel-free ejaculates ( $n=300,11-25 /$ boar) of $\geq$ $200 \times 10^{6}$ sperm $/ \mathrm{ml}$ and $85 \%$ total motile spermatozoa (TMS) were diluted in one step with a commercial semen extender (BTS, Minitub-Germany) to $30 \times 10^{6}$ sperm $/ \mathrm{ml}$, packaged in $100 \mathrm{ml}$ insemination doses and stored at $17-18{ }^{\circ} \mathrm{C}$ for $24 \mathrm{~h}$. Stored semen with at least 75\% TSM was then used for AI of multiparous sows in post-weaning standing estrus. Briefly, each sow was checked for heat twice a day. Once detected in standing heat, sows were further stimulated by back pressure and inseminated twice, $12 \mathrm{~h}$ and $24 \mathrm{~h}$ after the standing heat. Furthermore, after $24 \mathrm{~h}$ of semen storage doses of some ejaculates ( $n=90,4-6 /$ boar) were transported at $17-18{ }^{\circ} \mathrm{C}$ to the AI laboratory and assessed for sperm progressive motility (SPM), sperm chromatin instability (SCI), live morphologically normal spermatozoa (LMNS) and head morphometry of LMNS. It is worthy to note that we employed assays of SCI and LMNS in the current study in view of their correlation with fertility and ease of use together with the potential of integration of these assays into the routine work of AI centers with limited equipment (Tsakmakidis et al. 2010).

\subsection{Evaluation of seminal parameters}

\subsubsection{Sperm concentration and motility}

Sperm concentration of fresh semen was measured by a precalibrated photometer (SpermaCue, Minitub-Germany). In preserved samples, $1 \mu \mathrm{l}$ of semen was diluted with $99 \mu \mathrm{l}$ of $3 \% \mathrm{NaCl}$ solution containing $0.02 \%$ eosin and sperm cell concentration was estimated using an improved Neubauer hemocytometer chamber. The percentage of TMS in fresh semen was subjectively examined (x 1000, phase-contrast microscope, Leica, Germany) after dilution $10 \mu \mathrm{l}$ of semen with $100 \mu \mathrm{l}$ of BTS extender at $37{ }^{\circ} \mathrm{C}$. In stored semen, the percentage of SPM was assessed using a computer-assisted cell motion analyzer (Strömberg Mika, Germany). Sperm cells with both VAP $>$ MVV and STR value $>70 \%$ were included in the percentage of SPM (VAP=average pathway velocity, $\mu \mathrm{m} / \mathrm{s} ; \mathrm{MVV}=$ medium VAT cut-off value; STR=straightness, VSL divided by VAP; VSL=velocity straight line, $\mu \mathrm{m} / \mathrm{s}$ ). Semen samples were diluted to $20 \times 10^{6} \mathrm{sperm} / \mathrm{ml}$ with BTS extender, incubated under aerobic conditions at $37{ }^{\circ} \mathrm{C}$ for 30 min and placed $(2 \mu \mathrm{l})$ onto a pre-warmed disposable 4-chamber slide (Leja Products B.V., The Netherlands). The image was digitalized through a camera mounted on a phase-contrast microscope (x 100) and at least 200 spermatozoa of a minimum of eight sequential fields were tracked and analyzed using the following settings: temperature $37^{\circ} \mathrm{C}$; depth $20 \mu \mathrm{m}$; velocity limit immotile $9 \mu \mathrm{m} / \mathrm{s}$; velocity limit local motile $15 \mu \mathrm{m} / \mathrm{s}$; linearity limit 90\%; maximum radius for circles $30 \mu \mathrm{m}$.

\subsubsection{Sperm chromatin structure}

The incidence of SCI was evaluated by the acridine orange test (AOT), as described by Tejada et al., (1984). AOT measures the susceptibility of sperm nuclear DNA to acid-induced denaturation in situ by quantifying the metachromatic shift of AO fluorescence from green (native/double-stranded DNA) to red (denatured/single-stranded DNA). Semen $(5 \mathrm{ml})$ was transferred to a $15-\mathrm{ml}$ conical plastic tube and centrifuged at $2400 \mathrm{xg}$ for $3 \mathrm{~min}$ at $25^{\circ} \mathrm{C}$. The sperm pellet was resuspended in phosphate buffer saline (PBS, $\mathrm{pH} 7.2$ ) to $100 \times 10^{6}$ cells $/ \mathrm{ml}$ and $20 \mu \mathrm{l}$ of sperm suspension was spread onto a pre-cleaned glass microscope slide and allowed to dry for $20 \mathrm{~min}$ at 37 ${ }^{\circ} \mathrm{C}$. The slides ( $\mathrm{n}=2 /$ ejaculate) were fixed in Carnoy's solution (300 ml methanol and $100 \mathrm{ml}$ glacial acetic acid) for $12 \mathrm{~h}$ at room temperature (RT). The slides were then removed from the fixative, allowed to dry for $10 \mathrm{~min}$ at $37^{\circ} \mathrm{C}$ and stained in the dark at RT for $5 \mathrm{~min}$ in a jar containing $\mathrm{AO}$ staining solution (prepared by mixing $40 \mathrm{ml}$ of $0.1 \%$ AO stock solution with $160 \mathrm{ml}$ of $2.1014 \%$ citric acid monohydrate solution and $10 \mathrm{ml}$ of $4.26 \% \mathrm{Na}_{2} \mathrm{HPO}_{4}$ solution, $\mathrm{pH} 2.5$ ). The slides were thoroughly rinsed by dipping in three changes of water bath, allowed to dry in the dark, mounted with anti-fading solution (0.2468 g Dabco ${ }^{\mathrm{TM}}$ (1, 4-Diazabicylo [2.2.2] octane) dissolved in $9 \mathrm{ml}$ of glycerol and $1 \mathrm{ml}$ PBS) and overlaid with a 24x50$\mathrm{mm}$ cover slip. The cover slip was then sealed with nail polish and all slides were examined (500 spermatozoa/slide) by a single observer under Leica fluorescence microscopy (I3 filter cube, blue excitation range, BP 450/490 excitation filter, dichromatic mirror 510 and LP 515 suppression filter, x1000). The slides were randomized and coded before examination and percentage of sperm heads; a spectrum of colors ranging from yellowish green to partially or entirely red was scored as cells susceptible to chromatin instability (Khalifa et al., 2008).

2.4.3. Sperm plasma membrane integrity, morphology and head morphometry

The proportions of live (intact plasma membrane) and morphologically normal spermatozoa (LMNS) were simultaneously assessed in smears ( $n=2 /$ ejaculate) stained with eosin-nigrosin stain as described by Barth and Oko (1989). Five hundred spermatozoa from each preserved ejaculate were examined under a bright-field microscope ( $x$ 1000). The deviations of sperm head, midpiece and principal piece, as well as the proximal and distal cytoplasmic droplets were 
scored as cells with morphological abnormalities. Furthermore, head dimensions of LMNS were manually examined in the same stained smears under phase-contrast microscopy equipped with a preset eye-piece ocular micrometer (x 1000). The length and width $(\mu \mathrm{m})$ of fifty live normal sperm heads from each preserved ejaculate (300 spermatozoa/boar; 1800 spermatozoa/age group) were measured.

\subsection{Fertility data analysis}

The farrowing rate (number of farrowed sows/number of inseminated ones) and the litter size (total number of piglets born alive/farrowed sow) of the pig farm were recorded and analyzed.

\subsection{Statistical analysis}

Data were analyzed according to the statistical procedures described by Petrie and Watson (2006), using the SPSS statistical package $\left(\right.$ SPSS $^{\circledR}$ 11.01.1 Statistical Software Inc., Chicago, 2001). The assumption of data normality was verified by the Kolmogorov-Smirnov test. All data were nearly normally distributed. The inter- and intra-assay coefficients of variation $(\mathrm{CV})$ were estimated for sperm head dimensions. Hypothesis testing was performed by parametric tests which included analysis of variance (ANOVA), chi-squared $\left(\chi^{2}\right)$ analysis and Pearson's correlation coefficient (PCC). Multifactorial ANOVA models were used to test the effects of age group, boar, semen ejaculate and their possible interactions on SPM, SCI, LMNS, sperm head dimensions and litter size. If ANOVA revealed significant differences among means (main effects), a planned multiple comparison of the means were performed using Duncan's multiple range test. The variations among farrowing rates due to age groups or boars were examined by $\chi^{2}$ analysis. PCC was used to measure degrees of association $(r)$ between sperm head morphometry and fertility traits. Differences were considered significant at $\mathrm{p}<0.05$. Unless otherwise stated, results were expressed in percentages and are presented as means \pm SEM.

\section{RESULTS}

The percentage of SPM varied between 64.20 and $83.60 \%$ among semen ejaculates and between $62.94 \pm 2.72 \%$ and $71.55 \pm 2.48 \%$ among boars ( $\mathrm{p}<0.05)$, with an overall mean value of $67.83 \pm 0.98 \%$. The effect of age (Table 1) and its interaction with boar or semen ejaculate on SPM were nonsignificant.

The incidence of SCI ranged between 0 and 10\% among semen ejaculates and between $0.16 \pm 0.05 \%$ and $5.20 \pm 1.32 \%$ among boars, with overall mean values of $2.16 \pm 0.46 \%$. The effect of boar $(p<0.001)$ and age $(p<0.05)$ on SCI was significant. Mature boars had a lower value $(1.62 \pm 0.30 \%)$ of SCI than those of the young $(3.51 \pm 0.76 \%)$ and old $(3.33 \pm 0.70 \%)$ boars (Table 1). No significant interactions were found between age group, boar and ejaculate on SCI.

The proportion of LMNS varied between 41 and $93.60 \%$ among semen ejaculates and between $45.81 \pm 1.32 \%$ and $80.26 \pm 1.76 \%$ among boars, with overall mean values of $65.40 \pm 1.25 \%$. Both boar and age significantly influenced the percentage of LMNS $(p<0.001)$. Semen samples of young $(59.29 \pm 2.28 \%)$ and mature $(61.48 \pm 3.03 \%)$ boars had lower values of LMNS than that $(72.67 \pm 2.89 \%)$ found in semen samples of the old boars (Table 1). The interactions between boar, age group and semen ejaculate on LMNS were statistically non-significant.

The overall mean value of sperm head length was $9.00 \pm 0.02$ $\mu \mathrm{m}(\mathrm{SD}=0.53 ; \mathrm{CV}=5.89 \%)$. The intra-assay $\mathrm{CV}$ ranged between $4.57 \%$ and $7.22 \%$. Head length varied between 7.50 and $10.5 \mu \mathrm{m}$ among semen ejaculates and between $8.77 \pm 0.06$ and $9.24 \pm 0.08 \mu \mathrm{m}$ among boars. Significant effects were found for boar $(p<0.001)$ and age $(p<0.03)$ on head length. Mature boars had lower mean values of sperm head length $(8.95 \pm 0.03$ $\mu \mathrm{m})$ than those of the young $(9.04 \pm 0.03 \mu \mathrm{m})$ and old $(9.06 \pm 0.03$ $\mu \mathrm{m})$ boars (Table 2). No significant interactions were found between boar, age group and ejaculate on sperm head length.

The overall mean value of sperm head width was $4.95 \pm 0.01$ $\mu \mathrm{m} \quad(\mathrm{SD}=0.24 ; \mathrm{CV}=4.85 \%)$. The intra-assay $\mathrm{CV}$ ranged between $3.33 \%$ and $6.85 \%$. Head width fluctuated between 4 and $6 \mu \mathrm{m}$ among semen ejaculates and between $4.80 \pm 0.05$ and $4.99 \pm 0.04 \mu \mathrm{m}$ among boars. The effect of boar $(\mathrm{p}<0.01)$ and age $(\mathrm{p}<0.001)$ on head width was significant. As shown in Table 3, mature boars had lower mean values of sperm head width $(4.93 \pm 0.01 \mu \mathrm{m})$ than that $(4.98 \pm 0.01 \mu \mathrm{m})$ of the old boars. Nevertheless, sperm head length of young boars $(4.95 \pm 0.02 \mu \mathrm{m})$ did not vary significantly from those of the mature and old boars. Furthermore, boar and ejaculate by age interactions on head width were non-significant.

The overall values of farrowing rate and live litter size were $84.77 \%$ and $10.87 \pm 0.23$. Farrowing rate varied between $59.30 \%$ and $87.67 \%$ among boars $\left(\mathrm{P}<0.005 ; \mathrm{x}^{2}=9.87\right)$. As indicated in Table 4 , young boars had a significantly $(\mathrm{p}<0.001)$ lower

TABLE 1

Effect of boar age on incidence (mean \pm SEM) of sperm progressive motility (SPM), chromatin stability (SCI) and live morphologically normal spermatozoa (LMNS) in 24-h liquid-stored semen

\begin{tabular}{lccccc}
\hline \multicolumn{1}{c}{ Age group } & N1 & N2 & SPM $(\%)$ & SCI $(\%)^{*}$ & LMNS $(\%){ }^{* *}$ \\
\hline Young boars (7-10 months, $\mathrm{n}=5)$ & 6 & 30 & $68.81 \pm 1.63 \mathbf{a}$ & $3.51 \pm 0.76 \mathbf{a}$ & $59.29 \pm 2.28$ a \\
Mature boars (18-33 months, $\mathrm{n}=7)$ & $4-5$ & 30 & $69.33 \pm 1.75 \mathbf{a}$ & $1.62 \pm 0.30 \mathbf{b}$ & $61.48 \pm 3.03$ a \\
Old boars (51-61 months, $\mathrm{n}=5)$ & 6 & 30 & $66.92 \pm 2.01 \mathbf{a}$ & $3.33 \pm 0.70 \mathbf{a}$ & $72.67 \pm 2.89 \mathbf{b}$ \\
Overall & $4-6$ & 90 & $67.83 \pm 0.98$ & $2.16 \pm 0.46$ & $65.40 \pm 1.25$ \\
\hline
\end{tabular}

Values with dissimilar letters within columns are significantly different $\left(\mathrm{P}<0.05^{*}\right.$ and $\left.<0.001^{* *}\right)$. The effect of boar on SPM, SCI and LMNS is significant $(\mathrm{P}<0.05-$ $0.001)$. N1 and N2 denote number of ejaculates used per boar and per group, respectively. 
TABLE 2

Effect of boar age on head length $(\mu \mathrm{m})$ of live morphologically normal spermatozoa in 24-h liquid-stored semen

\begin{tabular}{lcccccc}
\hline \multicolumn{1}{c}{ Age group } & N1 & N2 & Mean & SD & SEM & CV (\%) \\
\hline Young boars (7-10 months, $\mathrm{n}=5)$ & 6 & 30 & $9.04 \mathrm{a}$ & 0.46 & 0.03 & 5.09 \\
Mature boars (18-33 months, $\mathrm{n}=7)$ & $4-5$ & 30 & $8.95 \mathrm{~b}$ & 0.38 & 0.03 & 4.25 \\
Old boars (51-61 months, $\mathrm{n}=5)$ & 6 & 30 & $9.06 \mathrm{a}$ & 0.35 & 0.03 & 3.86 \\
Overall & $4-6$ & 90 & 9.00 & 0.53 & 0.02 & 5.89 \\
\hline
\end{tabular}

Values with dissimilar letters are significantly different $(\mathrm{P}<0.03)$. The effect of boar on sperm head length is significant $(\mathrm{P}<0.001)$. N1 and $\mathrm{N} 2$ denote number of ejaculates used per boar and per group, respectively.

TABLE 3

Effect of boar age on head width $(\mu \mathrm{m})$ of live morphologically normal spermatozoa in 24-h liquid-stored semen

\begin{tabular}{lcccccc}
\hline \multicolumn{1}{c}{ Age group } & N1 & N2 & Mean & SD & SEM & CV $(\%)$ \\
\hline Young boars (7-10 months, $\mathrm{n}=5)$ & 6 & 30 & $4.95 \mathrm{ab}$ & 0.27 & 0.02 & 5.45 \\
Mature boars (18-33 months, $\mathrm{n}=7)$ & $4-5$ & 30 & $4.93 \mathrm{~b}$ & 0.25 & 0.01 & 5.07 \\
Old boars (51-61 months, $\mathrm{n}=5)$ & 6 & 30 & $4.98 \mathrm{a}$ & 0.16 & 0.01 & 3.21 \\
Overall & $4-6$ & 90 & 4.95 & 0.24 & 0.01 & 4.85 \\
\hline
\end{tabular}

Values with dissimilar letters are significantly different $(P<0.001)$. The effect of boar on sperm head length is significant $(P<0.01)$. N1 and $N 2$ denote number of ejaculates used per boar and per group, respectively.

TABLE 4

Effect of boar age on fertility of liquid-stored semen

\begin{tabular}{lcccc}
\hline \multicolumn{1}{c}{ Age group } & $\mathrm{N} 1$ & $\mathrm{~N} 2$ & Farrowing rate $(\%)$ & Live litter size (mean \pm SEM) \\
\hline Young boars (7-10 months, $\mathrm{n}=5)$ & 11 & 55 & $65.00(117 / 180) \mathrm{a}$ & $11.62 \pm 0.51 \mathrm{a}$ \\
Mature boars (18-33 months, $\mathrm{n}=7)$ & 25 & 175 & $87.24(1259 / 1443) \mathrm{b}$ & $10.53 \pm 0.25 \mathrm{a}$ \\
Old boars (51-61 months, $\mathrm{n}=5)$ & 14 & 70 & $84.74(372 / 439) \mathrm{b}$ & $11.13 \pm 0.23 \mathrm{a}$ \\
Overall & $11-25$ & 300 & $84.77(1748 / 2062)$ & $10.87 \pm 0.23$ \\
\hline
\end{tabular}

Values with dissimilar letters within columns are significantly different $(P<0.001 ; \chi 2=29.99-61.42)$. The effect of boar on farrowing rate is significant $(P<0.005)$. $\mathrm{N}$ and N2 denote number of ejaculates used per boar and per group, respectively.

farrowing rate $(65 \%)$ compared to those of mature $(87.24 \%$; $\left.x^{2}=61.42\right)$ and old $\left(84.74 \% ; x^{2}=29.99\right)$ boars. There was no significant difference between farrowing rates of mature and old boars, and the age of the boar had no significant effect on litter size (Table 4). Furthermore, boar and ejaculate by age interactions on litter size were non-significant.

Pearson correlation analysis did not show significant relationships between head length of LMNS and farrowing rate $(r=-0.04)$ or litter size $(r=-0.24)$. Likewise, there were no relationships $(p>0.05)$ between head width of LMNS and farrowing rate $(\mathrm{r}=0.20)$ or litter size $(\mathrm{r}=0.02)$.

\section{DISCUSSION}

Many factors including age could affect boar semen quality. The present study investigated effect of boar age on semen parameters and fertility. Significant differences were detected among boar age groups. Meanwhile, the non-significant age by boar and age by ejaculate interactions indicate that influences of boar and ejaculate were homogenously distributed among studied age groups. To our knowledge, there are no previous studies that have investigated boar age in relation to SCI.

In dairy bulls, Hallap et al. (2005) reported that animal age did not significantly influence SCI and total sperm morphological abnormalities. However, Karabinus et al. (1990) recorded a high incidence of chromatin instability and a low proportion of intact acrosomes in spermatozoa of young bulls. Furthermore, in a recent study on dairy sheep in our lab, Lymberopoulos et al. (2010) observed that mature rams had significantly lower values of sperm hyperactive motility and peroxidized sperm, greater percentages of sperm with intact plasma membrane, functional mitochondria and condensed chromatin, as well as greater lambing rate and ewe prolificacy. These results are in accordance with the results of our investigation, in which young boars demonstrated higher values of sperm morphological abnormalities, chromatin instability and sperm head length than mature boars after $24 \mathrm{~h}$ of semen storage. All these characteristics reflected in a significantly lower farrowing rate compared to the other groups. 
In addition, high SCI without reduction of farrowing rate was noticed in old boars. Considering that this phenomenon has been extensively studied in humans, these results are in agreement with previous studies that reported a higher DNA fragmentation in aged men (Wyrobek et al., 2006; Rybar et al., 2011). It is known that aging induces apoptosis in the epididymis, which seems to be caused by the fall of testosterone levels and is probably related to an increase of oxidative stress in tissues (Jara et al., 2004). It has been stated by Sailer et al. (1996) that abnormal chromatin structure may lead to problems in sperm nuclear packaging material, which can be related to morphologically abnormal spermatozoa. This was noticed in our study with respect to young boars, but not in old boars; SCI was also at a high level in this group. Therefore, more uninvestigated age-related factors are involved in spermatozoa production and function.

From the literature it is clear that a DNA fragmentation index (percentage of abnormal vs. normal cells for DNA fragmentation) beyond $6 \%$ may lead to reduced farrowing rate and/or decreased average total number of pigs born per litter (Didion et al., 2009). In the present study the percentage of SCI was less than $6 \%(3.51 \%$ and $3.33 \%$ for young and old boars, respectively). Moreover, Boe-Hansen et al. (2008) demonstrated that differences in litter size can be observed with thresholds as low as $2.1 \%$ or $3.0 \%$ for the DNA fragmentation index in liquid-stored boar semen. In our study no differences in litter size were found, but we tested crossbred boars of different ages, while in the previous study Hampshire, Danish Large White and Landrace boars were used. Furthermore, Waberski et al. (2011) reported no effect of DNA fragmentation index greater than $5 \%$ compared to that of less than $5 \%$ on farrowing rate and litter size, using ejaculates from Pietrain boars of mean age 36 months. This is consistent with our results of boars with similar age concerning the fertility data (mature boar group). In the present study, the SCI of the mature boars was less than $5 \%(1.62 \%)$, while the fertility measures remained at acceptable levels (farrowing rate, $87.24 \%$ and live litter size, 10.53).

In general, our study revealed that the susceptibility of boar spermatozoa to SCI was dependent on boar age. Young and old boars were more susceptible to SCI compared to mature boars and this property had a negative effect on the farrowing rate but not on the number of piglets born live. However, the increase of chromatin instability of old boars was not associated with a decrease in farrowing rate as observed in young boars. An explanation could be that the higher percentage of LMNS found in semen of old boars compared to young ones counterbalanced the detrimental effect of SCI. More studies are needed to rationalize the impact, or to associate the above-mentioned parameter with lower farrowing rates observed after AI with semen of young boars.

Spermatozoa differ in shape and dimensions among species and even between and within individuals (Thurston et al., 2001). Gil et al. (2009) suggested that boar spermatozoa head morphometry influenced the motility characteristics. According to Smital (2009) the highest incidence of sperm with pear-shaped heads occurred in boars up to 12 months of age and the highest incidence of sperm with simple bent tails occurred in boars older than 30 months. The results obtained in the present study demonstrated differences among boar age groups in LMNS and sperm head dimensions. The sperm head of mature boars was found to be significantly shorter than those of the other groups, and the sperm head of old boars was significantly wider than those of the mature boars. However, no significant relationship was found between sperm head length or width and farrowing rate. These results indicate that this level of differences in sperm head dimensions is not a sensitive marker to explain the variation in farrowing rates observed among boar age groups. To our knowledge, this is the first study which analyzed the effect of boar age on sperm head dimensions. Nevertheless, similar studies have been conducted in other animal species. Marti et al. (2011), aiming at using morphometry as an indicator of ram sexual maturity, pointed out a direct relationship between sexual maturity and sperm head dimensions and shape. They observed significant differences for all variables (area, perimeter, length and width) of sperm head dimensions between young and middle-aged or old rams, while except for length, all morphometric dimension values decreased with increasing ram age.

In conclusion, the results of this study revealed significant differences among boars of different ages in terms of chromatin stability, morphology and sperm head morphometry. Young and old boars are more susceptible to SCI compared to mature boars, while the risk of obtaining unacceptable farrowing rates is higher after AI with semen from young than from mature and old boars. Therefore, boar age is an important physiological factor that contributes to the success of AI with preserved semen and should be taken into account.

\section{REFERENCES}

ABU HASSAN ABU D, FRANKEN DR, HOFFMAN B, HENKEL R (2011) Accurate sperm morphology assessment predicts sperm function. Andrologia (in press).

AHMADI A, NG SC (1999) Fertilizing ability of DNA-damaged spermatozoa. J Exp Zool 284:696-704.

ARAUJO AB, WITTERT GA (2011) Endocrinology of the aging male. Best Pract Res Clin Endocrinol Metab 25:303-319.

BARTH AD, OKO RJ (1989) Preparation of semen for morphological examination. In: Abnormal morphology of bovine spermatozoa. 1st ed., Iowa State University Press. pp:8-12.

BOE-HANSEN GB, CHRISTENSEN P, VIBJERG D, NIELSEN MB, HEDEBOE AM (2008) Sperm chromatin structure integrity in liquid stored boar semen and its relationships with field fertility. Theriogenology 69:728736.

BOE-HANSEN GB, ERSBOLL AK, GREVE T, CHRISTENSEN P (2005) Increasing storage time of extended boar semen reduces sperm DNA integrity. Theriogenology 63:2006-2019.

CASSUTO NG, HAZOUT A, HAMMOUD I, BALET R, BOURET D, BARAK Y, JELLAD S, PLOUCHART JM, SELVA J, YAZBECK C (2011) Correlation between DNA defect and sperm-head morphology. Reprod BioMed Online 24:211-218.

EVENSON DP, THOMPSON L, JOST L (1994) Flow cytometric evaluation of boar semen by the sperm chromatin structure assay as related to cryopreservation and fertility. Theriogenology, 41:637-651.

DIDION BA, KASPERSON KM, WIXON RL, EVENSON DP (2009) Boar fertility and sperm chromatin structure status: a retrospective report. J Androl 30:655-660.

GIL MC, GARCÍA-HERREROS M, BARÓN FJ, APARICIO IM, SANTOS AJ, GARCÍA-MARÍN LJ (2009) Morphometry of porcine spermatozoa and its functional significance in relation with the motility parameters in fresh semen. Theriogenology, 71:254-263.

HALLAP T., NAGY S., HAARD M., JAAKMA U., JOHANNISSON A., RODRIGUEZ-MARTINEZ H. (2005) Sperm chromatin stability in frozen-thawed semen is maintained over age in AI bulls. Theriogenology 63:1752-1763.

HINGST O, BLOTTNER S, FRANZ C (1995) Chromatin condensation in cat spermatozoa during epididymal transit as studied by aniline blue and acridine orange staining. Andrologia 7: 275-279.

HUANG YH, LO LL, LIU SH, YANG TS (2010) Age-related changes in semen quality characteristics and expectations of reproductive longevity in Duroc boars. Anim Sci J 81:432-437. 
JARA M, CARBALLADA R, ESPONDA P (2004) Age-induced apoptosis in the male genital tract of the mouse. Reproduction 127:359-366.

KARABINUS DS, EVENSON DP, JOST LK, BAER RK, KAPROTH MT (1990) Comparison of semen quality in young and mature Holstein bulls measured by light microscopy and flow cytometry. J Dairy Sci 73:2364-2371.

KENNEDY BW, WILKINS JN (1984) Boar, breed and environmental factors influencing semen characteristics of boars used in artificial. Can J Anim Sci 64:833-843.

KHALIFA TAA, REKKAS CA, LYMBEROPOULOS AG, SIOGA A, DIMITRIADIS I, PAPANIKOLAOU TH (2008) Factors affecting chromatin stability of bovine spermatozoa. Anim Reprod Sci 104:143-163.

LYMBEROPOULOS AG, TSAKMAKIDIS IA, KHALIFA TAA (2010) Effect of ram age on structural and functional competence of frozen-thawed spermatozoa in dairy sheep. Reprod Dom Anim 45:572-578.

MARTÍ JI, APARICIO IM, GARCÍA-HERREROS M (2011) Head morphometric changes in cryopreserved ram spermatozoa are related to sexual maturity. Theriogenology 75:473-481.

MIDZAK AS, CHEN H, PAPADOPOULOS V, ZIRKIN BR (2009) Leydig cell aging and the mechanisms of reduced testosterone synthesis. Mol Cell Endocrinol 299:23-31.

PEÑA FJ, SARAVIA F, GARCÍA-HERREROS M, NÚÑEZ-MARTÍNEZ I, TAPIA JA, JOHANNISSON A, WALLGREN M, RODRÍGUEZMARTÍNEZ H (2005) Identification of sperm morphometric subpopulations in two different portions of the boar ejaculate and its relation to postthaw quality. J Androl 26:716-723.

PETRIE A, WATSON P (2006) Statistics for veterinary and animal science. In (2nd ed): Blackwell Publishing Ltd, Oxford, UK. pp:174-190.

RODRÍGUEZ-MARTÍNEZ H (2003) Laboratory semen assessment and prediction of fertility: still utopia? Reprod Dom Anim 38:312-318.

RODRÍGUEZ-MARTÍNEZ H, COURTENS JL, KVIST U, PLOEN L (1990) Immunocytochemical localization of nuclear protamine in boar spermatozoa during epididymal transit. J Reprod Fertil 89:591-595.

RYBAR R, KOPECKA V, PRINOSILOVA P, MARKOVA P, RUBES J (2011) Male obesity and age in relationship to semen parameters and sperm chromatin integrity. Andrologia 43:286-291.
SAILER BL, JOST LK, EVENSON DP (1996) Bull sperm head morphometry related to abnormal chromatin structure and fertility. Cytometry 24:167-173.

SARAVIA F, NÚÑEZ-MARTÍNEZ I, MORÁN JM, SOLER C, MURIEL A, RODRÍGUEZ-MARTÍNEZ H, PEÑA FJ (2007) Differences in boar sperm head shape and dimensions recorded by computer-assisted sperm morphometry are not related to chromatin integrity. Theriogenology 68:196-203.

SINGH NP, MULLER CH, BERGER RE (2003) Effects of age on DNA doublestrand breaks and apoptosis in human sperm. Fertil Steril 80:1420-1430.

SMITAL J (2009) Effects influencing boar semen. Anim Reprod Sci 110:335-346.

SUN JG, JURISICOVA A, CASPER RF (1997) Detection of deoxyribonucleic acid fragmentation in human sperm: correlation with fertilization in vitro. Biol Reprod 56:602-607.

TEJADA RI, MITCHELL JC, NORMAN A, MARIK JJ, FRIEDMAN S (1984) A test for the practical evaluation of male fertility by acridine orange (AO) fluorescence. Fertil Steril 42:87-91.

THURSTON LM, WATSON PF, MILEHAM AJ, HOLT WV (2001) Morphologically distinct sperm subpopulations defined by Fourier shape descriptors in fresh ejaculates correlate with variation in boar semen quality following cryopreservation. J Androl 22:382-394.

TSAKMAKIDIS IA, LYMBEROPOULOS AG, KHALIFA TA (2010): Relationship between sperm quality traits and field-fertility of porcine semen. J Vet Sci 11:151-154.

WABERSKI D, DIRKSEN G, WEITZE KF, LEIDING C, HAHN R (1990) Field studies of the effect of sperm motility and morphology on the fertility of boars used for insemination. Tierarztl Prax 18:591-594.

WABERSKI D, SCHAPMANN E, HENNING H, RIESENBECK A, BRANDT $\mathrm{H}$ (2011) Sperm chromatin structural integrity in normospermic boars is not related to semen storage and fertility after routine AI. Theriogenology 75:337-345.

WOLF J, SMITAL J (2009) Effects in genetic evaluation for semen traits in Czech Large White and Czech Landrace boars. Czech J Anim Sci 54:349-358.

WYROBEK AJ, ESKENAZI B, YOUNG S, ARNHEIM N, TIEMANN-BOEGE I, JABS EW, GLASER RL, PEARSON FS, EVENSON D (2006) Advancing age has differential effects on DNA damage, chromatin integrity, gene mutations, and aneuploidies in sperm. Proc Natl Acad Sci USA 103:9601-9606. 